\title{
Health Outcome Prioritization in Alzheimer's Disease: Understanding the Ethical Landscape
}

\author{
Alex McKeown ${ }^{\mathrm{a}, *}$, Andrew Turner ${ }^{\mathrm{b}}$, Zuzanna Angehrn ${ }^{\mathrm{c}}$, Dianne Gove ${ }^{\mathrm{d}}$, Amanda Ly ${ }^{\mathrm{e}}$, \\ Clementine Nordon ${ }^{\mathrm{f}}$, Mia Nelson ${ }^{\mathrm{g}}$, Claire Tochel ${ }^{\mathrm{g}}$, Brent Mittelstadt ${ }^{\mathrm{h}}$, Alex Keenan ${ }^{\mathrm{i}}$, \\ Michael Smith ${ }^{\mathrm{j}}$ and Ilina Singh ${ }^{\mathrm{a}}$ \\ ${ }^{a}$ Department of Psychiatry and Wellcome Centre for Ethics and Humanities, University of Oxford, Oxford, UK \\ ${ }^{\mathrm{b}}$ The National Institute for Health Research Applied Research Collaboration West [NIHR ARC West] at University \\ Hospitals Bristol NHS Foundation Trust, University of Bristol, Bristol, UK \\ ${ }^{\mathrm{c}}$ Certara, Loerrach, Germany \\ ${ }^{\mathrm{d}}$ Alzheimer Europe, Luxembourg \\ ${ }^{\mathrm{e}}$ MRC Integrative Epidemiology Unit \& Centre for Academic Mental Health, University of Bristol, Bristol, UK \\ ${ }^{\mathrm{f}}$ CESP, INSERM U1178, Paris, France \\ ${ }^{\mathrm{g}}$ Usher Institute of Population Health Sciences and Informatics, University of Edinburgh, Edinburgh, UK \\ ${ }^{\mathrm{h}}$ Oxford Internet Institute, University of Oxford, Oxford, UK \\ ${ }^{\mathrm{i} J a n s s e n}$ Pharmaceutica NV, Titusville, NJ, USA \\ ${ }^{\mathrm{j}}$ Alzheimer Scotland Centre for Policy and Practice, University of the West of Scotland, Paisley, Scotland, UK
}

Accepted 8 June 2020

\begin{abstract}
.
Background: Dementia has been described as the greatest global health challenge in the 21 st Century on account of longevity gains increasing its incidence, escalating health and social care pressures. These pressures highlight ethical, social, and political challenges about healthcare resource allocation, what health improvements matter to patients, and how they are measured. This study highlights the complexity of the ethical landscape, relating particularly to the balances that need to be struck when allocating resources; when measuring and prioritizing outcomes; and when individual preferences are sought.

Objective: Health outcome prioritization is the ranking in order of desirability or importance of a set of disease-related objectives and their associated cost or risk. We analyze the complex ethical landscape in which this takes place in the most common dementia, Alzheimer's disease.

Methods: Narrative review of literature published since 2007, incorporating snowball sampling where necessary. We identified, thematized, and discussed key issues of ethical salience.

Results: Eight areas of ethical salience for outcome prioritization emerged: 1) Public health and distributive justice, 2) Scarcity of resources, 3) Heterogeneity and changing circumstances, 4) Knowledge of treatment, 5) Values and circumstances, 6) Conflicting priorities, 7) Communication, autonomy and caregiver issues, and 8) Disclosure of risk.
\end{abstract}

\footnotetext{
*Correspondence to: Alex McKeown, Department of Psychiatry and Wellcome Centre for Ethics and Humanities, University of Oxford, Warneford Hospital, Warneford Lane, Oxford OX3 7JS, UK. Tel.: +44 (0) 1865618 325; E-mail: alexander.mckeown@psych.ox.ac.uk.
} 
Conclusion: These areas highlight the difficult balance to be struck when allocating resources, when measuring and prioritizing outcomes, and when individual preferences are sought. We conclude by reflecting on how tools in social sciences and ethics can help address challenges posed by resource allocation, measuring and prioritizing outcomes, and eliciting stakeholder preferences.

Keywords: Alzheimer's disease, dementia, ethics, health priorities

\section{INTRODUCTION}

Health outcome prioritization is the ranking in order of desirability or importance of a set of diseaserelated objectives and their associated cost or risk, obtained collaboratively with or from patients and their carers. It can occur at several levels and by different stakeholders, including: between a doctor [1], nurse [2], pharmacist [3], or other healthcare professional and an individual patient; within families of an individual or individuals with AD [4, 5]; between cohorts of patients and researchers in a randomized controlled trial (RCT) [6]; by national healthcare systems such as the National Health Service (NHS) and associated resource allocation bodies such as the National Institute for Clinical and Care Excellence (NICE) [7]; and at the international level between governments when collaborating on meeting global health priorities [8]. Situations in which outcome prioritization is useful include: 1) regulatory scenarios for assessing benefit to risk ratio by, for example, establishing which endpoints would be the most relevant to measure in an RCT; 2) economic scenarios considering 'value for money', as the finitude of resources precludes being able to fund every intervention; 3) questions of individual benefit-torisk ratios to establish what kind of care a particular patient wishes to receive.

Alzheimer's disease (AD) is the most common type of dementia and a 'global public health priority'. [9, 10] Some evidence suggests the prevalence of all-cause dementia rates may be declining [11]; however, with an aging population and older people living longer, the incidence of specific dementias such as $\mathrm{AD}$ may continue to rise [12]. The prospect of a global prevalence of 131.5 million [11] imposes a significant and growing costs, necessitating innovation in the management of dementia [13].

In this paper we describe and analyze the evidence base for the complex ethical landscape of health outcome prioritization as it takes place in the most common form of dementia, AD. The paper was produced as an Ethical, Legal, and Social Implications (ELSI) output for the European Union and Innova- tive Medicines Initiative (IMI)-funded consortium project, ROADMAP: Real World Outcomes across the AD spectrum for better care [14]. The authorial team is comprised of researchers working on the ROADMAP project, including clinicians, scientists, and patient representatives with expertise in $\mathrm{AD}$, led by three bioethicists with expertise in analyzing ethical issues in healthcare and medicine. Although there are several types of dementia, ROADMAP focuses exclusively on AD dementia; as such, the paper analyses ethical issues in health outcome prioritization for $\mathrm{AD}$ alone. The research questions we seek to answer are:

- What are the ethical issues that drive outcome prioritization?

- What balances need to be struck when prioritizing outcomes?

Our analysis highlights eight key areas of ethical salience to fair outcome prioritization in AD. There is currently no curative treatment for $\mathrm{AD}$; as such, while we assume that if it were possible to cure $\mathrm{AD}$, most individuals would be likely to prioritize this over other outcomes, since no cure exists, the review focuses on how outcomes other than this might be weighed and prioritized. The themes that emerged from our analysis illustrate the challenges of realizing outcomes and making prioritization choices. Given the growing global prevalence of $\mathrm{AD}$ analysis of these ethical issues is timely and necessary.

\section{METHODS}

A narrative review based on a mixture of structured and ad-hoc searching of academic literature was conducted. This is a narrative, rather than systematic, review, capturing the landscape of the debate rather than surveying the prevalence of different views in the literature. While establishing the relative prevalence of different themes or theories would be independently interesting, our aim was the identification of these in the literature rather than their relative prominence. This choice reflects our presumption that the 
normative legitimacy of ethical challenges is not a function of the frequency of their discussion.

Relevant manuscripts were identified in several stages. First, a structured search was carried out in January 2018 and updated in September 2019 across five academic indexes: EMBASE, PubMed (incl. MEDLINE), Scopus, Web of Science, and Google Scholar. The search identified articles with relevant titles using the search strings listed in Table 1.

The keyword search was limited to the "Article Title', for three reasons. First, a search of titles was likely to yield those articles most directly pertinent to our analysis. Second, additional snowball sampling via further references supplied by co-authors, and via screening of the references of already included studies identified further relevant research representing a broad range of stakeholders in AD. Third, a preliminary search of abstracts as well as titles yielded an extremely large sample that, on the basis of screening a sample of the papers returned, added noise but little value in relation to capturing the principles of the ethical debate, when compared to the results of a title only search. This is to say that numerous papers are available which happen to use some of our keywords, but on reviewing are not pieces of research which are about ethics in any way that is relevant to our purpose. For example, a title and abstract search on SCOPUS for articles published in English for the specified date range using key terms ethic* priorit* and health* returned 6,820 documents.

To ensure a manageable and contemporary sample, we restricted our search to literature in peer-reviewed journal articles and conference proceedings published from 2007, ten years before work on the study began. Additionally, we only reviewed articles written in English. Article abstracts and, if needed, full texts were then assessed for relevance by a single reviewer. A subset of 20 articles was screened by a second reviewer, and the results of this screening by the two reviewers were compared for consistency in assessing the relevance of the study to the purposes of the review. This comparison yielded an agreement of $85 \%$, which indicated a reliable degree of consistency, and discussion of the reasons for the discrepancies in the remaining helped to refine shared understanding of the criteria when further screening was carried out. Finally, we screened the references of included articles to identify further relevant articles and allowed all authors to suggest further relevant articles not identified by the initial search ("snowball sampling").

49 articles were retrieved by the initial search. 36 of these were rejected, either due to being judged insufficiently relevant after review; because they were

Table 1

Structured search results

\begin{tabular}{|c|c|c|}
\hline Database & Search Strings & $\overline{\text { \# Returned }}$ \\
\hline \multirow[t]{2}{*}{ EMBASE } & $\begin{array}{l}\text { [ethic* AND outcome*] AND [priorit* OR health* OR alzheimer* OR } \\
\text { dementia*] }\end{array}$ & 7 \\
\hline & $\begin{array}{l}\text { [ethic* AND priorit*] AND [outcome* OR health* OR alzheimer* OR } \\
\text { dementia*] }\end{array}$ & 19 \\
\hline \multirow[t]{2}{*}{$\begin{array}{l}\text { PubMed [incl. } \\
\text { MEDLINE] }\end{array}$} & $\begin{array}{l}\text { [ethic* AND outcome*] AND [priorit* OR health* OR alzheimer* OR } \\
\text { dementia*] }\end{array}$ & 7 \\
\hline & $\begin{array}{l}\text { [ethic* AND priorit*] AND [outcome* OR health* OR alzheimer* OR } \\
\text { dementia*] }\end{array}$ & 21 \\
\hline \multirow[t]{2}{*}{ Scopus } & $\begin{array}{l}\text { [ethic* AND outcome*] AND [priorit* OR health* OR alzheimer* OR } \\
\text { dementia*] }\end{array}$ & 10 \\
\hline & $\begin{array}{l}\text { [ethic* AND priorit*] AND [outcome* OR health* OR alzheimer* OR } \\
\text { dementia*] }\end{array}$ & 23 \\
\hline \multirow[t]{2}{*}{ Web of Science } & $\begin{array}{l}\text { [ethic* AND outcome*] AND [priorit* OR health* OR alzheimer* OR } \\
\text { dementia*] }\end{array}$ & 4 \\
\hline & $\begin{array}{l}\text { [ethic* AND priorit*] AND [outcome* OR health* OR alzheimer* OR } \\
\text { dementia*] }\end{array}$ & 17 \\
\hline \multirow{4}{*}{$\begin{array}{l}\text { Google Scholar [strings } \\
\text { modified for } \\
\text { compliance with search } \\
\text { engine formatting] }\end{array}$} & allintitle: [ethics OR ethical] AND [outcome OR outcomes] AND & 11 \\
\hline & [prioritization OR prioritisation OR priority OR health OR healthcare & \\
\hline & $\begin{array}{l}\text { OR health-related OR health-care OR alzheimer's OR alzheimer OR } \\
\text { dementia] }\end{array}$ & \\
\hline & $\begin{array}{l}\text { allintitle: [ethics OR ethical] AND [prioritization OR prioritisation OR } \\
\text { priority OR priorities] AND [outcome OR outcomes OR health OR } \\
\text { healthcare OR health-related OR health-care OR alzheimer's OR } \\
\text { alzheimer OR dementia] }\end{array}$ & 18 \\
\hline TOTAL (Unique papers) & & 49 \\
\hline
\end{tabular}


irretrievable; or having been published in a language other than English, leaving 13 included and reviewed here. Snowball sampling and the introduction of additional previously collected articles of contextual relevance yielded a further 119 references, giving a total of 125 documents pertaining to ethical issues in outcome prioritization in AD reviewed and discussed. Three references pertaining to research methodology were also provided for support in study design and data analysis.

Analysis of the papers aimed to map the landscape of prevalent ethical themes in the academic and clinical discussion around outcome prioritization in healthcare generally and AD specifically. To identify themes for discussion, a pre-defined thematic framework was not used; rather, themes emerging from the literature were identified [15]. Each paper was read in full, key passages were highlighted that addressed ethical issues or concepts, understood here as areas of 'right' and 'wrong' or competing values and normative interests. Highlighted segments were labelled with codes reflecting the lead author's interpretation of the text [16]. Our analytic approach was informed by established 'realist' and 'meta-narrative' methods of qualitative synthesis, drawing on previous ethics-focused review studies for guidance [17-19]. Discussion of the themes occurred between co-authors, who come from disciplines including philosophy, epidemiology, psychology and psychiatry, public health, as well as the pharmaceutical industry. Themes were reviewed and discussed at each draft iteration of the study until consensus was reached and there was agreement among all of the authors that the themes accurately reflected the findings of the analysis. This required five such iterations in total, at which point the thematic categorization was finalized.

\section{RESULTS}

Below, we outline eight areas of ethical salience in outcome prioritization that emerged from the analysis. These eight areas are not themselves ranked in order of priority or importance; rather they reflect the landscape of matters of key ethical importance that arose from the review: 1) Public health and distributive justice, 2) Scarcity of resources, 3) Heterogeneity and changing circumstances, 4) Evidence, 5) Values and circumstances, 6) Conflicting priorities, 7) Communication, autonomy and caregiver issues, and 8) Disclosure of risk.

\section{Public health and distributive justice}

A key ethical aspect of contemporary AD management is the shift toward public health prevention [10] away from clinical medicine [20], to contain the costs of supporting an expanding and aging population in which AD prevalence will increase [21-23]. However, the benefits of a preventive approach should not be overstated [20,24]; rather, the benefits of promoting general health advice may extend to dementia [10]. This shift is important for determining an ethical prioritization of outcomes in two respects.

First, public information about how to reduce the risk of dementia through lifestyle modifications from early life onwards affects the relationship between the state and its citizens [25]. Pressure to make certain choices may be viewed as an infringement of liberty $[26,27]$, particularly where the state establishes policies that expect individuals to modify their behavior; or prioritize treatment based on following preventative recommendations. Moreover, recommending lifestyle modifications that provide no guarantee to prevent $\mathrm{AD}$ may be viewed as unacceptably paternalistic and corrode trust.

Second, the application of Quality Adjusted Life Years (QALYs) to individual priorities may not adequately capture the subjectively bound nature of 'quality of life' or 'well-being', despite the centrality of both to ensuring a successful outcome for people with $\mathrm{AD}$, given that personal evaluations of concepts such as these differ [28, 29]. Furthermore, 'benefit' and 'value' may be interpreted differently. From a health economic perspective it is essential to attach a particular price to a particular level of benefit [30], however, the priorities of individuals with $\mathrm{AD}$ are likely to differ from other stakeholders, such as patients, their carers, health care professionals, providers, and payers of medical treatments [31].

\section{Scarcity of resources}

Outcome prioritization requires distributing limited resources to achieve desired outcomes. How these distribution decisions are made differs geographically. For example, in the UK, NICE prioritizes cost-effectiveness, whereas cost-effectiveness does not inform decision-making in Germany, and in the Netherlands it informs decision-making but only above a certain price threshold (very cheap drugs do not attract scrutiny) [32].

Irrespective of particular metrics used, the finitude of resources means that some people will be 
denied access to interventions that would benefit them [33-35]. This is ethically significant since the needs of some will be de-prioritized in favor of the needs of others, and the resulting gap may conflict with the clinical duty of care (this also holds for prioritization between people with the same condition and people with different conditions). As Hermeren et al. [36] summarize baldly, to prioritize is inevitably to say 'no' to somebody.

This is especially acute in the AD context, in which many people are unable to derive significant value, given that no curative treatments are yet available and evidence for the effectiveness of preventative interventions is weak. In light of this, some have concluded that the greatest need is for high-quality long term care, and similarly high-quality support for family carers, such that the lives of people with $\mathrm{AD}$ and their families are made as satisfying as possible in the absence of any treatment that would decisively reverse the disease [5, 37]. Indeed, research carried out by Kelly et al. (2015, p. 990) [38] with people with dementia, their carers, clinicians, and other health professional finds preferences of this kind in the top ten overall prioritized outcomes across all groups.

Encouragingly, for the findings of our own analysis, there is also significant parity with the Kelly et al. [Ibid.] study insofar as ethical dilemmas over finite resources report shared concerns, for example: negotiating the balance of benefits between pharmacological and lifestyle or social interventions; evaluating the value of early diagnosis in light of its psychological impact in the absence of a cure; how to optimize outcomes for people with advanced dementia at the end of life; and how to also support carers of people with AD as well as people with AD themselves.

\section{Heterogeneity and changing circumstances}

Prioritization decisions are ultimately concerned with both outcomes and endpoints, which are related but distinct parameters. Outcomes denote measured effects of treatment, whereas endpoints are preidentified targets of a study built into its design [39]. From an international perspective, the outcomes and endpoints considered important may differ, depending on characteristics of particular markets [39]. Moreover, the definition, diagnostic cut-off and mechanism of measuring the numerous potential outcomes and endpoints continue to be debated; and the difficulty of determining preferences for these-for example living longer, declining more slowly, or dying sooner before more serious incapacity-is compounded by the plethora of available assessment tools. A further challenge in $\mathrm{AD}$, and in the context of other conditions, is that assessment tools measuring a wide range of domains including memory, spatial orientation, semantic processing, speech, emotion, mood, apathy, aggression, and mobility [40-42] are not ideally sensitive or specific and so do not yield perfect validity either in earlier and preclinical stages of the disease [40] or in more severe stages [41, 42].

In addition to this heterogeneity in assessment tools, changing background circumstances also affect prioritization decisions. Prioritization is also made complex by the heterogeneity of $\mathrm{AD}$ itself, in that the disease affects different individuals in different ways, in different cultural contexts, and at different stages of the disease; indeed, priorities are likely to differ in line with the progression of the disease, since the impact of MCI, for example, is less severe than very advanced $\mathrm{AD}$ later in life [12, 41]. As such the $\mathrm{AD}$ community itself cannot be assumed to be homogeneous with respect to how members of it are affected by the disease [42, 43], which underlines the risk of assuming that the priorities of one $\mathrm{AD}$ population subgroup is necessarily representative of other subgroups or the $\mathrm{AD}$ population at large. Moreover, not only are resources for people with AD limited (as above), but their availability is not necessarily constant. For example, external or short-term political factors and election cycles can affect both health policy and budgets, which shape prioritization decisions [44]. Equally, prioritization is shaped by new advances in medical science that expand what is therapeutically possible. Furthermore, global trends towards population growth and increasing life expectancy may mean a future in which more people are competing for fewer resources [45]. Outcome prioritization should therefore be viewed as an ongoing process, requiring reflection and revision, according to changing circumstances, as needs and options change [46-48].

\section{Knowledge of treatment}

Determining what counts as fair prioritization of outcomes depends partly on what needs to be known to make the relevant decision $[1,49]$. Data from randomized trials is considered the 'gold standard' for establishing efficacy; however, there are a number of challenges that make it expensive and time consuming to test the efficacy (or effectiveness) of a drug, and 
make it difficult to determine optimal clinical practice for long term treatment management in AD.

First, there is the challenge of attrition compromising the validity and/or generalizability of results from trials [50]. There is evidence that older, sicker individuals in particular are more likely to drop out of studies [51, 52], die before the trial is concluded or to discontinue the study treatment due to adverse effects.

Second, people in symptomatic stages of AD are typically older and more likely to have comorbidities, making them complex [53-55]. RCTs of new drug products may investigate drug-drug interactions to some degree, but this is not always exhaustive. Data from RCTs about drug-drug combinations may be underpowered or simply unavailable. Since interventions may have trade-offs between desirable effects and undesirable side-effects, weighing these is less straightforward where comorbidities requiring different types of treatment are present [56]. Polypharmacy is common, without clinicians fully knowing the risk of harm due to lack of evidence. Indeed, separate studies are designed to address these issues [57], and knowledge of the mechanism of action of certain drugs contributes usefully to decision-making. Notwithstanding the challenges outlined, therefore, clinicians are not uninformed when prescribing certain drugs. Rather, the biggest challenge arises when patients have multiple comorbidities which all require treatment [58] since it may become necessary to prioritize the treatment of some rather than other in order to realize an all-thingsconsidered, rather than ideally, desirable outcome. As such, ensuring an optimal balance of outcomes in the context of chronic disease in old age is particularly challenging [59]. This uncertainty poses a further challenge for realizing priority outcomes which depend on the effectiveness of a particular drug.

\section{Values and circumstances}

The importance of patients being able to make their own decisions is reflected in the contemporary centrality of 'patient-centered care' [60, 61]. Properly respecting the values and circumstances of patients does not mean swapping a paternalistic approach for an equally polar norm in which patients have absolute autonomy over all courses of action [62, 63]. Nevertheless there is an inevitable imbalance between the clinical expertise of doctors and patients who are experts in their own experience and the subject of the disease and its treatment [64-66]. As such, patient-centered care and prioritization of outcomes in $\mathrm{AD}$ should be conceived as a collaboration known as 'shared decision-making' [67, 68].

Knowledge-related power imbalances underline the ethical importance of remembering that it is the patient who must have the final say. Indeed, this is especially important in the case of $\mathrm{AD}$, where treatment options are limited. For example, if faced with the prospect of cognitive decline a patient may, for example, decide not to accept a pacemaker to prevent heart failure. It is not obvious in such circumstances that the decision against prolonging life as long as possible is either irrational or to be avoided. As van Summeren et al. [3] report, a dilemma often faced by patients, carers, and clinicians is how to balance factors such as the benefit of palliation of symptoms and maintenance of life or independence against the discomfort caused by the side effects of a potentially complicated drug regime. Examples such as this thus remind us of the primacy of the AD patient's right to choose, even within a shared decision-making model.

\section{Conflicting priorities}

Complications arise when determining and combining preferences. For example, the difference between qualitative and quantitative findings present a challenge when pooling and attempting to weigh different forms of evidence $[69,70]$. To mitigate this, preference elicitation techniques [71-73] exist to help individuals to arrive at a decision or ranking of the various outcomes and permutations.

Ordering outcomes according to their desirability may not be straightforward, given the different ways in which a disease and its symptoms may affect daily living and wellbeing. For example, in patients with multiple conditions or comorbidities, countervailing factors will need to be taken into account [10] to arrive at what is, overall, the best balance between benefits and risks of one approach to treatment rather than another [74, 75]. Ordering outcomes is also complex because the 'best' balance of risks and benefits may be plural, that is, there may be more than one 'right' decision in any given scenario. This is especially pertinent in the $\mathrm{AD}$ context, given that no cure is available at present. Were there curative treatments it may be easier to calibrate the relative desirability of different options since, presumably, reversing the disease would be always be prioritized over other outcomes. In the absence of curative treatment, deciding 
on the 'right' course of action must be made by the careful weighing of other, suboptimal, options.

Ethical challenges in outcome prioritization also emerge when priorities conflict, for example between short- and long-term treatment goals, considering that the development of drugs and tests is slow and resource intensive [76], even when research funding prioritizes a particular condition [77]. Moreover, there may be challenges in involving all relevant stakeholders in the prioritization process [78]. For example, factors such as linguistic barriers and insensitivity to different cultural values mean that minority ethnic groups are under-represented in research $[8$, 79-81].

There may also be intractable conflicts of priorities in relation to decisions concerning the end of life. Qualitative research by Goodman et al. [5] reminds us that for many people with dementia, death may be preferable to a severely impaired life with dementia. Since family members and carers cannot (legally) hasten death to bring an end to unwanted suffering, it is not obvious how such wishes can be meaningfully accommodated.

As Hunter [82] writes, questions about whose responsibility it is to engage in the process of prioritizing outcomes are also ethically contentious. This creates a further set of practical ethical complexities around the balance of duties and responsibilities between patients, carers, society at large, clinicians, policy makers, health economists, and other bodies with a stake in optimizing care. For instance, prioritization can be complex when making choices regarding prevention or disease progression, such as whether to provide treatment to those who are most in need, or those who would benefit the most. There is no straightforward way to resolve dilemmas such as this, which reminds us we cannot assume that priorities will be uniform and agreed between patients, their carers, clinicians, and the wider general public [47, $48,83]$. Indeed, such dilemmas may be fundamentally unresolvable, given that, ultimately, one group's interests will be relatively de-prioritized.

We can go further still than this to reinforce the point if we keep in mind that allocation dilemmas in a specific context such as $\mathrm{AD}$ are not unique in their complexity, since in the vast majority of instances, notwithstanding certain paradigmatically immoral acts such as torture or rape, ethical judgements are always contestable. Since there is no objectively agreed standard of measurement or value as is more readily available in the sciences, it is the nature of moral deliberation that grounds for rational disagreement can never be completely extinguished. Returning to the extant context of health outcome prioritization in $\mathrm{AD}$, therefore, this general characteristic of ethical discourse underwrites the claim that what counts as a successful decision and legitimate prioritization of outcomes will consist in the fastidiousness of the process by which the decision was reached in terms of considering the views of as wide a range of stakeholders as possible [84], rather than the decision itself.

\section{Communication, autonomy, and caregiver issues}

AD impedes communication [84], cognition [85], autonomous decision-making [86], social participation [87], and independence [88] and has a psychological and emotional impact affecting relationships and perceptions of self and personhood [89, 90] as the disease progresses from mild cognitive impairment (MCI) onwards [4, 48]. This becomes increasingly significant as the disease advances and compromises more aspects of life, as family carers may often need to spend an increasing amount of time supporting their relative with $\mathrm{AD}$ and making decisions on their behalf on the basis of what they take to be the relative's wishes $[4,91]$.

Questions of self-determination are immediately relevant in this context. Seeking out the preferences of people with $\mathrm{AD}$ and other dementias is crucial as far as it is possible to do so [92], and it is important not to assume that people with dementia are necessarily unable to speak for or represent themselves, albeit that sensitivity and flexibility must be shown to the varying lengths of time that someone with $\mathrm{AD}$ may need to make choices or communicate their wishes [93]. For example, at the end of life it is of the utmost importance that the dying person's wishes are understood as explicitly as possible in advance [94-96], moreover, it should not be assumed that people will be unable to express their preferences in some form, even at later stages of the disease or at the end of life [11,97]. This is vital when considering who has a say in determining which outcomes matter: firstly to ensure that those who can contribute do so; and secondly to ensure that first-hand experiences of different disease stages are represented. This is an issue of both fairness-in that there should be no systematic exclusion based on assumptions about capacity at particular stages; and validity - in that the actual priorities of patients are heard above the hypothetical priorities of those imagining being in such circumstances. 
The completion of advance directives by individuals before their dementia becomes too advanced to communicate their preferences towards the end of life are one option for negotiating likely future communication issues [98]. However, these are not without potential ethical problems; for example that they are often left incomplete such that the individual's wishes are uncertain or unknown to carers and others [95]; and the validity of advance directives can be disputed or undermined given that it is possible an individual's preferences change after they are no longer able to communicate this to others [92]. As such, when attempting to make prioritization decisions in the later stages of $\mathrm{AD}$, it is important to keep in mind that advance directives, while undoubtedly a vital tool for eliciting preferences, are nevertheless fallible.

Given the progressive, degenerative nature of $\mathrm{AD}$, it can become increasingly difficult to know the priorities and preferences of the person affected. Often caregivers, whether professional or unpaid, family members, or partners, are able to understand the affected person's wishes as their ability to clearly communicate their preferences diminishes [84, 99-101]. However, this presents a challenge for ensuring that carers properly represent the affected person's interests and, crucially, that they respect and protect the dignity of the person with dementia [102]. This is a considerable ethical challenge, as knowing what we ought to do for people with $\mathrm{AD}$ if their preferences are only indirectly discernible or require interpretation raises the risk of erroneous decisions. Again, the limitations of advance directives should also be taken into account in relation to this point.

People with AD are vulnerable if they cannot communicate effectively and may be more reliant on their carers to represent their interests. While most carers will do this, it cannot be assumed that all risks of misrepresentation or mistreatment are eliminated [103]. For example, carers' evaluations of the quality of life of people with $\mathrm{AD}$ are typically negative [104], but we cannot verify this precisely because of the impaired communication that the disease brings about. Similarly, there is evidence to suggest that carers wish patients to remain in the milder stages for as long as possible and decline rapidly toward the end to minimize the impact that it will have on them, but we cannot assume that this is what the person being cared for would also wish [105]. One reason may be that the burden and risk of isolation experienced by carers increases as the patient's disease progresses, and their judgement of the patient's quality of life can be negatively influenced by the deterioration in their own quality of life [106, 107]. Nevertheless, it is important here to consider carers as stakeholders with a legitimate voice of their own regarding outcome prioritization, separate from the extent to which they can reliably interpret the wishes of those for whom they are caring $[108,109]$.

\section{Disclosure of risk}

The risk of progressing from MCI to $\mathrm{AD}$ may be an important outcome for people in early stages of cognitive decline; however, the uncertainty of such predictions and the limited ability to act on it, make knowledge of one's risk ethically complex. For instance, although preclinical testing for $\mathrm{AD}$ is advancing in accuracy and scope [110], understanding the wishes of all those to whom such testing may be relevant is important for harm reduction [111] and ensuring individuals have the greatest scope for decision-making that they wish to have, whatever their decisions and preferences following risk disclosure might be. People identified at high risk of developing $\mathrm{AD}$, such as some MCI patients, will already feature in such considerations, since, as Rose [112] points out, the best indicator of major disease in future is often the existing presence of minor disease. Indeed, the current diagnostic guidelines state that $\mathrm{AD}$ dementia is preceded by MCI, and MCI is preceded by an asymptomatic preclinical AD phase [113]. However, as algorithms become better at predicting risk in asymptomatic individuals, namely, those who have biomarkers of the disease but no symptoms, those to whom this will become relevant will increase in line with the increasing accuracy of predicting $\mathrm{AD}$ at the asymptomatic stage.

In each group deemed at risk, the ethical ramifications of testing center on how individuals, and those close to them, should respond to risk information as well as what responsibilities fall on those disclosing the risk status. For example, this will extend to family members, as knowledge that a relative will or is likely to develop AD will affect their lives, not least because some of those family members or partners may have to become carers [43, 114]. Moreover, in the case of genetic risk factors for $\mathrm{AD}$ which can be identified at any age, such as $A P O E$, genetically related relatives may be faced with a decision about whether they too wish to undergo testing for presence of such markers [115].

These scenarios are ethically challenging as long as AD remains incurable. For example, while cognitively normal, asymptomatic, individuals may be able 
to reduce their risk of developing MCI or AD by making lifestyle changes in mid-life, there is an absence of high-quality, reliable evidence for the effectiveness of these changes, and as such they do not guarantee it $[116,117]$. As such, it cannot be assumed that individuals will necessarily prioritize receiving risk information in the absence of a guarantee that successful prevention is possible. Nevertheless, there may be benefits to early risk assessment and diagnosis, since it enables patients to more capably make legal and care arrangements and change their lifestyle so that they can maximize the time they have with significant others $[118,119]$ or to make plans to end their lives before dementia makes that impossible.

To the extent that a foundational duty of healthcare professionals is avoiding and preventing harm, it is necessary to keep in mind a broad conception of harm that encompasses not only physical and cognitive impairment caused by the progression of $\mathrm{AD}$, but psychological and emotional damage that may come to people by knowing their risk. It is straightforward to state that individuals are entitled to be informed of all the findings of their scan, however distressing these might be, if they wish to and understand the implications of what they might be told. However, it should not be assumed that, for example, cognitively normal but amyloid positive individuals [13] should automatically be informed of the results of their scan without prior discussion as to the individual's preferences for disclosure [120], as it may cause significant distress even if the information is sought. Indeed, amyloid positive individuals may live to old age [121] or die before developing notable symptoms, either because of another condition or an accident, even though there is a consensus among clinicians that these individuals would have developed dementia had death not intervened first. In these cases, it is important to elicit what an individual's preferences are with respect to $\mathrm{AD}$, relative to other health risks that they face, also taking into account how legal rights to the disclosure of information to individuals are framed in different jurisdictions.

Aside from the harms of the disease, therefore, disclosure may pose a risk of psychological and emotional harm to affected individuals [122], their carers and families, and the interpersonal relationships between them [123]. Finally, for individuals with private health coverage rather than the majority in the European context who depend on state health provision, known information relating to the risk of disease may affect individuals' insurance premiums and coverage and cover if they are obliged to disclose this to insurers [23, 64, 108, 109, 124], and a the risk of harm that may come from the exploitation of this information by insurers should be taken into account when balancing the priority of potential outcomes. The risks outlined are some of those adduced in arguments against dementia screening $[125,126]$ and help to demonstrate that although an assumption that diagnosis and knowledge of one's condition would and should always be one's priority may look prima facie reasonable, when subjected to scrutiny the situation reveals itself too complex for the assumption to be applicable or necessarily beneficial.

\section{DISCUSSION}

Our analysis indicates that the themes identified can be grouped into three larger arrangements of overlapping ethical issues in outcome prioritization, which we now discuss. We will also make some remarks about what normative approaches might be appropriate for negotiating them; for example, philosophical tools such as differing theories of justice can inform debate and decision-making in arriving at conclusions about how resources should be distributed; and (social) scientific tools such as quantitative and qualitative research methodologies can help to elicit personal perspectives that are required for understanding what outcomes are important to whom, and why. It is important to note here that there are research consortia which draw together and integrate these expertise toward developing fair and equitable methods of outcome prioritization in $\mathrm{AD}$, such as IMI EU EFPIA ROADMAP [14, 127]

The first group of issues relates to the importance of ensuring the adequacy of the procedures according to which finite resources are allocated. For example, if the needs of a certain group of people cannot be met because it would not be costeffective to do so, then it is important: first, that relevant professionals are trained to give individuals difficult and potentially distressing news; and second, that the commissioning process is thorough and comprehensively justified, with efforts to prevent geographical disparities, or 'postcode lotteries' in provision (themes 1, 2, 6, 7). Similarly, procedures for prioritizing outcomes must be able to respond effectively to advances in therapy and the consideration of these under whatever protocol for allocation is applied. If it is important to maximize the benefit from available treatments, then it commensurately important to ensure that potentially beneficial 
new developments can be incorporated into resource allocation decision procedures. For these kinds of considerations, we adopt the most general, macrolevel perspective. Given that due consideration for the correct balance of rights and responsibilities between the state and the individual falls within the purview of ethics, it is here that the philosophical tools derived from understanding competing theories of justice are instructive for negotiating resource allocation and prioritization dilemmas.

The second set of issues relates to the specific outcomes to be measured and prioritized and how to ensure that those measured are most important and meaningful to relevant stakeholders (themes 3, 4, 5, $7,8,9)$. Prioritization can only meet the needs and wishes of the affected parties the outcomes valued by the people to whom allocation decisions pertain are known. This may change at different stages of the disease and hence it is important also to have valid and reliable outcome assessment tools to measure the priority outcomes that are appropriate to these different stages. This obviates the need to elicit the preferences of people with $\mathrm{AD}$ and their carers, rather than assuming what outcomes are desired and in what order of preference. Moreover, as we pointed out, understanding what outcomes are prioritized and in what order is also complicated in view of the complexity of AD. Medications may have side-effects and/or drug-drug interactions that may affect the overall outcome for a patient, and since $\mathrm{AD}$ is largely a disease of old age it is frequently important to take comorbidities into account when attempting to attach a value to a particular outcome and course of action [34]. To the extent that a duty of prioritization decisions is to optimize outcomes for people with $\mathrm{AD}$, understanding the preferences of these people is a necessary step in discharging that duty. These demands can be met by qualitative and quantitative research methods in the form of interviews, focus groups, surveys, questionnaires, and digital data collection. As such, social science research tools can be usefully employed for seeking out and understanding individual preferences and the reasons behind them.

The careful application of these tools is also valuable for negotiating the third group of ethical challenges, which, like the issue of age-related comorbidities, is highly relevant to $\mathrm{AD}$, and concerns the way in which individual preferences are sought (themes 3, 7,8). AD can impair the ability of affected people to clearly make and convey their preferences and wishes, and so there is a potential ethical risk in not prioritizing outcomes in a way that meets the needs and wishes of those people. Furthermore, given that $\mathrm{AD}$ can impair communication, carers may need to make decisions on a patient's behalf, and there may be conflicting accounts of the patient's best interests. Adequate and ethically robust outcome prioritization processes depend partly on first having identified what is needed by and important to people with $\mathrm{AD}$, and as such the procedures used to elicit this information must be capable of doing so. Since cost-effectiveness decisions are necessarily utility-driven, unless preferences for outcomes are successfully elicited and appropriately quantified, there is a risk that these important qualitative aspects of $\mathrm{AD}$ are lost against the background of the aggregative method by which prioritization is directed.

\section{Limitations}

This is a non-systematic narrative review. One potential limitation may come from the type of conducted search, where only the titles were searched for presence of keywords. This limitation was mitigated by subsequent snowball sampling of further relevant manuscripts, which significantly increased the number of papers eligible for review. Another potential limitation may come from the single-reviewer process applied to this study at the abstract selection and initial full-text review stages. This limitation was to some extent mitigated by the iterative analysis process, where all contributors reviewed, discussed, and contextualized the results, reaching back to the original sources as needed; and by the reviewing of a subset of titles by a co-author and comparison of decisions for inclusion and exclusion. A further limitation is that since we have only used English language studies in this paper, we are unsure of the reliability of our findings for non-English speaking AD communities. However, this was unavoidable given the resources available to the authors.

A final limitation is that since the later stages of editing post-peer review were carried out during the initial lockdown phase of the 2020 COVID-19 pandemic, the authors are unable to review literature about the ethical implications of outcome prioritization in $\mathrm{AD}$ in the context of the current pandemic and potential future ones. Given that the paper is based on a review of the relevant literature, while ADrelevant studies produced in light of the pandemic will undoubtedly emerge, the paper has not been produced sufficiently long after the initial global infection for such material to be published made available for analysis. 
Nevertheless, we can make a tentative remark that it would be worthwhile to investigate in future work. It is likely that situations such as the COVID-19 pandemic may change what are considered acceptable trade-offs in outcome prioritization within the eight themes that we identify in this study. A possible concrete example of this might be accepting the additional safety risks associated with remote monitoring of people with $\mathrm{AD}$ living on their own, in order to shield them from the more immediate infectious disease risk that would come with usual levels of face-to-face contact.

\section{Conclusion}

Our analysis demonstrates the essential role that ethical deliberation plays in ensuring the just prioritization of outcomes. Given that discussions about how we 'should' allocate resources is an irreducibly normative question, expertise in ethical and philosophical reasoning are indispensable for a task such as this, irrespective of the fact that the task is an applied one and these kinds of expertise are putatively theoretical. Of course, the evidence to which we refer is similarly indispensable, since without empirical information about how and why different stakeholders prioritize outcomes in the way that they do, no rational negotiation of these towards a just outcome can be carried out. Nevertheless, what ought to be done cannot simply be read off these descriptive data. For this reason, allied with the compelling need to find new strategies for managing AD in view of the growing societal pressure that it is exerting, we conclude by reiterating the central role that ethical reflection contributes in decision-making processes regarding the prioritization of patient outcomes.

\section{ACKNOWLEDGMENTS}

This project has received funding from the Innovative Medicines Initiative 2 Joint Undertaking under grant agreement No. 116020 ["ROADMAP"]. This Joint Undertaking receives support from the European Union's Horizon 2020 research and innovation program and EFPIA. This project was conducted in collaboration with the Dementias Platform UK and the European Medical Informatics Framework. Alex McKeown is supported by The Wellcome Centre for Ethics and Humanities, which is supported by core funding from the Wellcome Trust [203132/Z/16/Z]; and the Medical Research Council Mental Health Data Pathfinder Award [MC_PC_17215].
Andrew Turner's time is supported by the National Institute for Health Research Collaboration for Leadership in Applied Health Research and Care West [NIHR CLAHRC West], now recommissioned as NIHR Applied Research Collaboration West [NIHR ARC West]. The views expressed are those of the authors and not necessarily those of the NHS, the NIHR or the Department of Health and Social Care.

Ilina Singh is supported by the Wellcome Trust [104825/Z/14/Z], and the Wellcome Centre for Ethics and Humanities, which is supported by core funding from the Wellcome Trust [203132/Z/16/Z]; and the NIHR Oxford Health Biomedical Research Centre [IS-BRC-1215-20005].

Authors' disclosures available online (https:// www.j-alz.com/manuscript-disclosures/19-1300r2).

\section{REFERENCES}

[1] Janssen IM, Gerhardus A, Schröer-Günther MA, Scheibler F (2015) A descriptive review on methods to prioritize outcomes in a health care context. Health Expect 18, 1873 1893.

[2] Edvardsson D, Winblad B, Sandman P (2008) Personcentred care of people with severe Alzheimer's disease: Current status and ways forward. Lancet Neurol 7, 362367.

[3] van Summeren JJ, Schuling J, Haaijer-Ruskamp FM, Denig P (2017) Outcome prioritisation tool for medication review in older patients with multimorbidity: A pilot study in general practice. Br J Gen Pract 67, e501-e506.

[4] Elliott BA, Gessert CE, Peden-McAlpine C (2009) Family decision-making in advanced dementia: Narrative and ethics. Scand J Caring Sci 23, 251-258.

[5] Goodman C, Amador S, Elmore N, Machen I, Mathie E (2013) Preferences and priorities for ongoing and end-oflife care: A qualitative study of older people with dementia resident in care homes. Int J Nurs Stud 50, 1639-1647.

[6] Pearce W, Raman S, Turner A (2015) Randomised trials in context: Practical problems and social aspects of evidencebased medicine and policy. Trials 16, 394.

[7] Steinbrook R (2008) Saying no isn't NICE — The travails of Britain's National Institute for Health and Clinical Excellence. N Engl J Med 359, 1977-1981.

[8] Pratt B, Sheehan M, Barsdorf N, Hyder AA (2018) Exploring the ethics of global health research priority-setting. BMC Med Ethics 19, 94.

[9] World Health Organization. Dementia: A public health priority. Towards a dementia plan: A WHO guide.

[10] Livingston G, Sommerlad A, Orgeta V, Costafreda SG, Huntley J, Ames D, Ballard C, Banerjee S, Burns A, Cohen-Mansfield J, Cooper C, Fox N, Gitlin LN, Howard R, Kales HC, Larson EB, Ritchie K, Rockwood K, Sampson EL, Samus Q, Schneider LS, Selbæk G, Teri L, Mukadam N (2017) Dementia prevention, intervention, and care. Lancet 390, 2673-2734.

[11] Robillard JM, Wu JM, Feng TL, Tam MT (2019) Prioritizing benefits: A content analysis of the ethics in dementia technology policies. J Alzheimers Dis 69, 897-904. 
[12] Langa KM (2015) Is the risk of Alzheimer's disease and dementia declining? Alzheimers Res Ther 7, 34.

[13] Solomon A, Mangialasche F, Richard E, Andrieu S, Bennett DA, Breteler M, Fratiglioni L, Hooshmand B, Khachaturian AS, Schneider LS, Skoog I, Kivipelto M (2014) Advances in the prevention of Alzheimer's disease and dementia. J Intern Med 275, 229-250.

[14] ROADMAP. ROADMAP Alzheimer.

[15] Braun V, Clarke V (2006) Using thematic analysis in psychology. Qual Res Psychol 3, 77-101.

[16] Patterson ME, Williams DR (2002) Collecting and analyzing qualitative data: Hermeneutic principles, methods and case examples. Sagemore Publishing, Champaign, IL.

[17] Pawson R, Greenhalgh T, Harvey G, Walshe K (2005) Realist review-a new method of systematic review designed for complex policy interventions. J Health Serv Res Policy 10 Suppl 1, 21-34.

[18] Greenhalgh T, Robert G, MacFarlane F, Bate P, Kyriakidou O, Peacock R (2005) Storylines of research in diffusion of innovation: A meta-narrative approach to systematic review. Soc Sci Med 61, 417-430.

[19] Ziebland S, Wyke S (2012) Health and illness in a connected world: How might sharing experiences on the internet affect people's health? Milbank $Q$ 90, 219-249.

[20] Yaffe K (2018) Modifiable risk factors and prevention of dementia. JAMA Intern Med 178, 281-282.

[21] Dartigues JF (2009) Alzheimer's disease: A global challenge for the 21st century. Lancet Neurol 8, 1082-1083.

[22] Kuljiš RO (2010) Grand challenges in dementia 2010. Front Neurol 1, 4.

[23] Winblad B, Amouyel P, Andrieu S, Ballard C, Brayne C, Brodaty H, Cedazo-Minguez A, Dubois B, Edvardsson D, Feldman H, Fratiglioni L, Frisoni GB, Gauthier S, Georges J, Graff C, Iqbal K, Jessen F, Johansson G, Jönsson L, Kivipelto M, Knapp M, Mangialasche F, Melis R, Nordberg A, Rikkert MO, Qiu C, Sakmar TP, Scheltens $\mathrm{P}$, Schneider LS, Sperling R, Tjernberg LO, Waldemar G, Wimo A, Zetterberg H (2016) Defeating Alzheimer's disease and other dementias: A priority for European science and society. Lancet Neurol 15, 455-532.

[24] Leshner AI, Landis S, Stroud C, Downey A (2017) Preventing Cognitive Decline and Dementia, National Academies Press, Washington, DC.

[25] Buchanan DR (2008) Autonomy, paternalism, and justice: Ethical priorities in public health. Am J Public Health 98 , 15-21.

[26] Jennings B (2009) Public health and liberty: Beyond the Millian Paradigm. Public Health Ethics 2, 123-134.

[27] Radoilska L (2009) Public health ethics and liberalism. Public Health Ethics 2, 135-145.

[28] Kind P, Lafata JE, Matuszewski K, Raisch D (2009) The use of QALYs in clinical and patient decision-making: Issues and prospects. Value Health 12, S27-S30.

[29] Hagell P, Reimer J, Nyberg P (2009) Whose quality of life? Ethical implications in patient-reported health outcome measurement. Value Health 12, 613-617.

[30] Rabins PV, Black BS (2007) Measuring quality of life in dementia: Purposes, goals, challenges and progress. Int Psychogeriatrics 19, 401-407.

[31] Tinetti ME, Studenski SA (2011) Comparative effectiveness research and patients with multiple chronic conditions. N Engl J Med 364, 2478-2481.

[32] Bauer A, Wittenberg R, Ly A, Gustavvson A, Sudlow C, Bexelius C, Bouvy J, Tochel C, Knapp M, Nelson M
(2018) Appendix III: LSE-led complementary work on priority outcomes for AD from the perspective of HTA (and regulatory) agencies. Supplementary report in support of D2.3 and D2.4.4 Disease progression and outcomes classification matrix.

[33] Khayatzadeh-Mahani A, Fotaki M, Harvey G (2013) Ethical theories and values in priority setting: A case study of the Iranian health system. Public Health Ethics 6, 60-72.

[34] Norheim OF (2016) Ethical priority setting for universal health coverage: Challenges in deciding upon fair distribution of health services. BMC Med 14, 75 .

[35] Kluge EHW (2007) Comparing healthcare systems: Outcomes, ethical principles, and social values. MedGenMed 9, 29

[36] Hermeren G(2009) Setting priorities versus managing closures: What is the ethically most sound way of handling changes in the health care system? Acta Oncol 38, 33-40.

[37] Lawrence V, Samsi K, Murray J, Harari D, Banerjee S (2011) Dying well with dementia: Qualitative examination of end-of-life care. Br J Psychiatry 199, 417-422.

[38] Kelly S, Lafortune L, Hart N, Cowan K, Fenton M, Brayne C (2015) Dementia priority setting partnership with the James Lind Alliance: Using patient and public involvement and the evidence base to inform the research agenda. Age Ageing 44, 985-993.

[39] Vellas B, Andrieu S, Sampaio C, Coley N, Wilcock G (2008) Endpoints for trials in Alzheimer's disease: A European task force consensus. Lancet Neurol 7, 436-450.

[40] Ritchie K, Ropacki M, Albala B, Harrison J, Kaye J, Kramer J, Randolph C, Ritchie CW (2017) Recommended cognitive outcomes in preclinical Alzheimer's disease: Consensus statement from the European Prevention of Alzheimer's Dementia project. Alzheimers Dement 13, 186-195.

[41] Robert P, Ferris S, Gauthier S, Ihl R, Winblad B, Tennigkeit F (2010) Review of Alzheimer's disease scales: Is there a need for a new multi-domain scale for therapy evaluation in medical practice? Alzheimers Res Ther 2, 24.

[42] Voisin T, Vellas B (2009) Diagnosis and treatment of patients with severe Alzheimer's disease. Drugs Aging 26, 135-144.

[43] Werner P, Korczyn AD (2008) Mild cognitive impairment: Conceptual, assessment, ethical, and social issues. Clin Interv Aging 3, 413-420.

[44] Geneau R, Stuckler D, Stachenko S, McKee M, Ebrahim S, Basu S, Chockalingham A, Mwatsama M, Jamal R, Alwan A, Beaglehole R (2010) Raising the priority of preventing chronic diseases: A political process. Lancet 376, 16891698.

[45] Kenny N, Joffres C (2008) An ethical analysis of international health priority-setting. Health Care Anal 16, 145-160.

[46] Gillain S, Dramé M, Lekeu F, Wojtasik V, Ricour C, Croisier J-L, Salmon E, Petermans J (2016) Gait speed or gait variability, which one to use as a marker of risk to develop Alzheimer disease? A pilot study. Aging Clin Exp Res 28, 249-255.

[47] McBrien B (2007) Exercising restraint: Clinical, legal and ethical considerations for the patient with Alzheimer's disease. Accid Emerg Nurs 15, 94-100.

[48] Werner P (2009) Israeli lay persons' views on prioritysetting criteria for Alzheimer's disease. Health Expect 12, 187-196.

[49] Daniels N (2016) Resource allocation and priority setting. In Public Health Ethics: Cases Spanning the Globe, 
Barrett D, Dawson A, Reis A, Ortmann LW, Saenz CBG, eds. Springer, pp. 61-94.

[50] Dumville JC, Torgerson DJ, Hewitt CE (2006) Reporting attrition in randomised controlled trials. BMJ 332, 969971.

[51] Dettori JR (2011) Loss to follow-up. Evid Based Spine Care J 2, 7-10.

[52] Bhamra S, Tinker A, Mein G, Ashcroft R, Askham J (2008) The retention of older people in longitudinal studies: A review of the literature. Qual Ageing Older Adults 9, 2735.

[53] Tinker A, Mein G, Bhamra S, Ashcroft R, Seale C (2009) Retaining older people in longitudinal research studies: Some ethical issues. Res Ethics 5, 71-74.

[54] Duthie A, Chew D, Soiza RL (2011) Non-psychiatric comorbidity associated with Alzheimer's disease. QJM 104, 913-920.

[55] Buchman AS, Boyle PA, Wilson RS, Tang Y, Bennett DA (2007) Frailty is associated with incident Alzheimer's disease and cognitive decline in the elderly. Psychosom Med 69, 483-489.

[56] Mrak RE (2009) Alzheimer-type neuropathological changes in morbidly obese elderly individuals. Clin Neuropathol 28, 40-45.

[57] Lewis LD (2010) Drug-drug interactions: Is there an optimal way to study them? Br J Clin Pharmacol 70, 781-783.

[58] Bunn F, Burn A-M, Goodman C, Rait G, Norton S, Robinson L, Schoeman J, Brayne C (2014) Comorbidity and dementia: A scoping review of the literature. BMC Med 12, 192.

[59] Maher RL, Hanlon J, Hajjar ER (2014) Clinical consequences of polypharmacy in elderly. Expert Opin Drug Saf 13, 57-65.

[60] Naylor MD, Karlawish JH, Arnold SE, Khachaturian AS, Khachaturian ZS, Lee VM-Y, Baumgart M, Banerjee S, Beck C, Blennow K, Brookmeyer R, Brunden KR, Buckwalter KC, Comer M, Covinsky K, Feinberg LF, Frisoni G, Green C, Guimaraes RM, Gwyther LP, Hefti FF, Hutton M, Kawas C, Kent DM, Kuller L, Langa KM, Mahley RW, Maslow K, Masters CL, Meier DE, Neumann PJ, Paul SM, Petersen RC, Sager MA, Sano M, Schenk D, Soares H, Sperling RA, Stahl SM, van Deerlin V, Stern Y, Weir D, Wolk DA, Trojanowski JQ (2012) Advancing Alzheimer's disease diagnosis, treatment, and care: Recommendations from the Ware Invitational Summit. Alzheimers Dement $\mathbf{8}$, 445-452.

[61] Sandman L, Munthe C (2010) Shared decision making, paternalism and patient choice. Health Care Anal 18, 6084.

[62] Richards T, Coulter A, Wicks P (2015) Time to deliver patient centred care. BMJ 350, h530.

[63] Badger JM, Ladd RE, Adler P (2009) Respecting patient autonomy versus protecting the patient's health. JONAS Healthc Law Ethics Regul 11, 120-124.

[64] Lantos J, Matlock AM, Wendler D (2011) Clinician integrity and limits to patient autonomy. JAMA 305, 495499.

[65] Joseph-Williams, N. Edwards, A. Elwyn G (2014) Power imbalance prevents shared decision making. BrMed J348, $17-18$.

[66] Koeck C (2014) Imbalance of power between patients and doctors. BMJ 349, g7485.

[67] Elwyn G, Frosch D, Thomson R, Joseph-Williams N, Lloyd A, Kinnersley P, Cording E, Tomson D, Dodd C, Rollnick S, Edwards A, Barry M (2012) Shared decision making: A model for clinical practice. J Gen Intern Med 27, 1361-1367.

[68] Barry MJ, Edgman-Levitan S (2012) Shared decision making - the pinnacle of patient-centered care. $N$ Engl J Med 366, 780-781.

[69] Bryman A (2007) Barriers to integrating quantitative and qualitative research. J Mix Methods Res 1, 8-22.

[70] Polit DF, Beck CT (2010) Generalization in quantitative and qualitative research: Myths and strategies. Int J Nurs Stud 47, 1451-1458.

[71] Danner M, Hummel JM, Volz F, van Manen JG, Wiegard B, Dintsios C-M, Bastian H, Gerber A, IJzerman MJ (2011) Integrating patients' views into health technology assessment: Analytic hierarchy process (AHP) as a method to elicit patient preferences. Int J Technol Assess Health Care 27, 369-375.

[72] Llewellyn-Thomas HA, Crump RT (2013) Decision support for patients. Med Care Res Rev 70, 50S-79S.

[73] Weernink MGM, Janus SIM, van Til JA, Raisch DW, van Manen JG, IJzerman MJ (2014) A systematic review to identify the use of preference elicitation methods in healthcare decision making. Pharmaceut Med 28, 175-185.

[74] Fried TR, McGraw S, Agostini JV, Tinetti ME (2008) Views of older persons with multiple morbidities on competing outcomes and clinical decision-making. $J \mathrm{Am}$ Geriatr Soc 56, 1839-1844.

[75] Maust DT, Kim HM, Seyfried LS, Chiang C, Kavanagh J, Schneider LS, Kales HC (2015) Antipsychotics, other psychotropics, and the risk of death in patients with dementia. JAMA Psychiatry 72, 438-445.

[76] Buckley JS, Salpeter SR (2015) A risk-benefit assessment of dementia medications: Systematic review of the evidence. Drugs Aging 32, 453-467.

[77] Grill JD, Galvin JE (2014) Facilitating Alzheimer disease research recruitment. Alzheimer Dis Assoc Disord 28, 1-8.

[78] Law E, Starr JM, Connelly PJ (2013) Dementia research - what do different public groups want? A survey by the Scottish Dementia Clinical Research Network. Dementia 12, 23-28.

[79] Woodall A, Morgan C, Sloan C, Howard L (2010) Barriers to participation in mental health research: Are there specific gender, ethnicity and age related barriers? $B M C$ Psychiatry 10, 103.

[80] UyBico SJ, Pavel S, Gross CP (2007) Recruiting vulnerable populations into research: A systematic review of recruitment interventions. J Gen Intern Med 22, 852-863.

[81] Dilworth-Anderson P, Hendrie HC, Manly JJ, Khachaturian AS, Fazio S, Social, Behavioral and Diversity Research Workgroup of the Alzheimer's Association (2008) Diagnosis and assessment of Alzheimer's disease in diverse populations. Alzheimers Dement 4, 305-309.

[82] Hunter D (2007) Am I my brother's gatekeeper? Professional ethics and the prioritisation of healthcare. $\mathrm{J} \mathrm{Med}$ Ethics 33, 522-526.

[83] Lejman E, Westerbotn M, Pöder U, Wadensten B (2013) The ethics of coercive treatment of people with dementia. Nurs Ethics 20, 248-262.

[84] Landau R, Werner S (2012) Ethical aspects of using GPS for tracking people with dementia: Recommendations for practice. Int Psychogeriatrics 24, 358-366.

[85] Barnes M, Brannelly T (2008) Achieving care and social justice for people with dementia. Nurs Ethics 15, 384-395.

[86] Cubit K (2010) Informed consent for research involving people with dementia: A grey area. Contemp Nurse $\mathbf{3 4}$, 230-236. 
[87] Smebye KL, Kirkevold M, Engedal K (2015) Ethical dilemmas concerning autonomy when persons with dementia wish to live at home: A qualitative, hermeneutic study. BMC Health Serv Res 16, 21.

[88] Brannelly $T$ (2011) That others matter: The moral achievement-care ethics and citizenship in practice with people with dementia. Ethics Soc Welf 5, 210-216.

[89] Shoval N, Auslander GK, Freytag T, Landau R, Oswald F, Seidl U, Wahl HW, Werner S, Heinik J (2008) The use of advanced tracking technologies for the analysis of mobility in Alzheimer's disease and related cognitive diseases. BMC Geriatr 8, 7.

[90] O'Connor D, Phinney A, Smith A, Small J, Purves B, Perry J, Drance E, Donnelly M, Chaudhury H, Beattie L (2007) Personhood in dementia care. Dementia 6, 121-142.

[91] Barrios PG, González RP, Hanna SM, Lunde AM, Fields JA, Locke DEC, Smith GE (2016) Priority of treatment outcomes for caregivers and patients with mild cognitive impairment: Preliminary analyses. Neurol Ther 5, 183192.

[92] Roger KS (2008) Priorities for people living with dementia: Education, counseling, research. Clin Interv Aging 3, 573-579.

[93] Burlá C, Rego G, Nunes R (2014) Alzheimer, dementia and the living will: A proposal. Med Health Care Philos 17, 389-395.

[94] Egede-Nissen V, Jakobsen R, Sellevold GS, Sørlie V (2013) Time ethics for persons with dementia in care homes. Nurs Ethics 20, 51-60.

[95] van der Steen JT, Radbruch L, Hertogh CM, de Boer ME, Hughes JC, Larkin P, Francke AL, Jünger S, Gove D, Firth P, Koopmans RT, Volicer L, European Association for Palliative Care (EAPC) (2014) White paper defining optimal palliative care in older people with dementia: A Delphi study and recommendations from the European Association for Palliative Care. Palliat Med 28, 197209.

[96] Weidemann EJ (2012) The ethics of life and death: Advance directives and end-of-life decision making in persons with dementia. J Forensic Psychol Pract 12, 81-96.

[97] National Institutes of Health. End-of-Life care for people with dementia. https://www.nia.nih.gov/health/end-lifecare-people-dementia

[98] Centers for Disease Control and Prevention. CDC Brief: Addressing Stigma Associated with Alzheimer's Disease and Other Dementias: Role of the Public Health and Aging Services Network.

[99] Barnes M, Henwood F (2015) Inform with care: Ethics and information in care for people with dementia. Ethics Soc Welf 9, 147-163.

[100] Flores YG, Hinton L, Barker JC, Franz CE, Velasquez A (2009) Beyond familism: A case study of the ethics of care of a latina caregiver of an elderly parent with dementia. Health Care Women Int 30, 1055-1072.

[101] Tranvåg O, Petersen KA, Nåden D (2016) Crucial dimensions constituting dignity experience in persons living with dementia. Dementia 15, 578-595.

[102] Tranvåg O, Petersen KA, Nåden D (2013) Dignitypreserving dementia care. Nurs Ethics 20, 861-880.

[103] Robinson JA, Crawford GB (2010) Do palliative patients and carers agree about patients' psychological functioning? Palliat Support Care 8, 69.

[104] Conde-Sala JL, Garre-Olmo J, Turró-Garriga O, LópezPousa S, Vilalta-Franch J (2009) Factors related to perceived quality of life in patients with Alzheimer's disease: The patient's perception compared with that of caregivers. Int J Geriatr Psychiatry 24, 585-594.

[105] Zucchella C, Bartolo M, Bernini S, Picascia M, Sinforiani E (2015) Quality of life in Alzheimer disease. Alzheimer Dis Assoc Disord. 29, 50-54.

[106] Nelson M, Smith M, Dias A, Gove D, Bintener C, Ly A, Tochel C, Sudlow C, Bexelius C, Gustavsson A (2018) Appendix I: Patient and public involvement consultations. Supplementary report in support of D2.3 and D2.4 Disease progression and outcomes classification matrix.

[107] Vellone E, Piras G, Talucci C, Cohen MZ (2008) Quality of life for caregivers of people with Alzheimer's disease. $J$ Adv Nurs 61, 222-231.

[108] Rosness TA, Mjørud M, Engedal K (2011) Quality of life and depression in carers of patients with early onset dementia. Aging Ment Health 15, 299-306.

[109] van der Vorm A, Rikkert MO, Vernooij-Dassen M, Dekkers W (2008) Genetic research into Alzheimer's disease: A European focus group study on ethical issues. Int J Geriatr Psychiatry 23, 11-15.

[110] van der Vorm A, Vernooij-Dassen MJFJ, Kehoe PG, Olde Rikkert MGM, van Leeuwen E, Dekkers WJM (2009) Ethical aspects of research into Alzheimer disease. A European Delphi Study focused on genetic and nongenetic research. J Med Ethics 35, 140-144.

[111] Dubois B, Hampel H, Feldman HH, Scheltens P, Aisen P, Andrieu S, Bakardjian H, Benali H, Bertram L, Blennow K, Broich K, Cavedo E, Crutch S, Dartigues J-F, Duyckaerts C, Epelbaum S, Frisoni GB, Gauthier S, Genthon R, Gouw AA, Habert M-O, Holtzman DM, Kivipelto M, Lista S, Molinuevo J-L, O’Bryant SE, Rabinovici GD, Rowe C, Salloway S, Schneider LS, Sperling R, Teichmann M, Carrillo MC, Cummings J, Jack CR (2016) Preclinical Alzheimer's disease: Definition, natural history, and diagnostic criteria. Alzheimers Dement 12, 292-323.

[112] Jack CR, Albert MS, Knopman DS, McKhann GM, Sperling RA, Carrillo MC, Thies B, Phelps CH, Phelps $\mathrm{CH}$ (2011) Introduction to the recommendations from the National Institute on Aging-Alzheimer's Association workgroups on diagnostic guidelines for Alzheimer's disease. Alzheimers Dement 7, 257-262.

[113] Rose G (2001) Sick individuals and sick populations. Int J Epidemiol 30, 427-432.

[114] Sperling RA, Karlawish J, Johnson KA (2013) Preclinical Alzheimer disease - the challenges ahead. Nat Rev Neurol 9, 54-58.

[115] Brodaty H, Donkin M (2009) Family caregivers of people with dementia. Dialogues Clin Neurosci 11, 217-218.

[116] Genin E, Hannequin D, Wallon D, Sleegers K, Hiltunen M, Combarros O, Bullido MJ, Engelborghs S, De Deyn P, Berr C, Pasquier F, Dubois B, Tognoni G, Fiévet N, Brouwers N, Bettens K, Arosio B, Coto E, Del Zompo M, Mateo I, Epelbaum J, Frank-Garcia A, Helisalmi S, Porcellini E, Pilotto A, Forti P, Ferri R, Scarpini E, Siciliano G, Solfrizzi V, Sorbi S, Spalletta G, Valdivieso F, Vepsäläinen S, Alvarez V, Bosco P, Mancuso M, Panza F, Nacmias B, Bossù $P$, Hanon $O$, Piccardi $P$, Annoni G, Seripa D, Galimberti D, Licastro F, Soininen H, Dartigues J-F, Kamboh MI, Van Broeckhoven C, Lambert JC, Amouyel P, Campion D (2011) APOE and Alzheimer disease: A major gene with semi-dominant inheritance. Mol Psychiatry 16, 903-907.

[117] Lövdén M, Xu W, Wang H-X (2013) Lifestyle change and the prevention of cognitive decline and dementia. Curr Opin Psychiatry 26, 239-243. 
[118] Flicker L (2010) Modifiable lifestyle risk factors for Alzheimer's disease. J Alzheimers Dis 20, 803-811.

[119] Weimer DL, Sager MA (2009) Early identification and treatment of Alzheimer's disease: Social and fiscal outcomes. Alzheimers Dement 5, 215-226.

[120] Prince M (2017) Progress on dementia-leaving no one behind. Lancet 390, e51-e53.

[121] Lingler JH, Klunk WE (2013) Disclosure of amyloid imaging results to research participants: Has the time come? Alzheimers Dement 9, 741-744.e2.

[122] Aizenstein HJ, Nebes RD, Saxton JA, Price JC, Mathis CA, Tsopelas ND, Ziolko SK, James JA, Snitz BE, Houck PR, Bi W, Cohen AD, Lopresti BJ, DeKosky ST, Halligan EM, Klunk WE (2008) Frequent amyloid deposition without significant cognitive impairment among the elderly. Arch Neurol 65, 1509-1517.

[123] Draper B, Peisah C, Snowdon J, Brodaty H (2010) Early dementia diagnosis and the risk of suicide and euthanasia. Alzheimers Dement 6, 75-82.

[124] Porteri C, Albanese E, Scerri C, Carrillo MC, Snyder HM, Martensson B, Baker M, Giacobini E, Boccardi M,
Winblad B, Frisoni GB, Hurst S (2017) The biomarkerbased diagnosis of Alzheimer's disease. 1-ethical and societal issues. Neurobiol Aging 52, 132-140.

[125] Davis DS (2017) Ethical issues in Alzheimer's disease research involving human subjects. J Med Ethics 43, 852856.

[126] Brayne C, Fox C, Boustani M (2007) Dementia screening in primary care. JAMA 298, 2409-2411.

[127] Le Couteur DG, Doust J, Creasey H, Brayne C (2013) Political drive to screen for pre-dementia: Not evidence based and ignores the harms of diagnosis. BMJ 347, f5125.

[128] Gallacher J, De Reydet De Vulpillieres F, Amzal B, Angehrn Z, Bexelius C, Bintener C, Bouvy JC, Campo L, Diaz C, Georges J, Gray A, Hottgenroth A, Mittelstadt B, Potashman MH, Reed C, Sudlow C, Thompson R, Tockhorn-Heidenreich A, Turner A, Van Der Lei J, Visser PJ, ROADMAP Consortium (2019) Challenges for optimizing real-world evidence in Alzheimer's Disease: The ROADMAP Project. J Alzheimers Dis 67, 495-501. 